\title{
A MATERNIDADE E O FEMINISMO INTERSECCIONAL DEBATIDO NO CANAL DE PODCAST MAMILOS
}

\author{
MOTHERHOOD AND INTERSECTIONAL FEMINISM DEBATED ON THE MAMILOS PODCAST
}

\section{RESUMO}

Neste artigo, analisamos a produção cultural de representações sobre maternidade, valendo-nos dos aportes do chamado Feminismo Interseccional, a partir de discussões ocorridas em um programa do canal de podcast Mamilos. Nossa proposta é revisitar o material coletado para uma dissertação de mestrado, produzida em uma linha de pesquisa atrelada às práticas pedagógicas, enfocando, aqui, aspectos relacionados ao Feminismo Interseccional. Argumentamos que os sujeitos aprendem a ser quem são na interação com diversos artefatos da mídia, embasadas por autoras e autores dos Estudos Culturais, tais como Giroux (2003), Kincheloe \& Steinberg (2004), Camozzato \& Costa (2013), Camozzato (2014), Camozzato; Carvalho; Andrade (2016), que têm dedicado seu tempo ao estudo das chamadas pedagogias culturais, potente ferramenta de análise. Após voo panorâmico, no qual apresentamos, brevemente, a pesquisa original, apontamos alguns dos direcionamentos revistos, salientando que esta revisão colocou em diálogo conceitos dos Estudos Culturais com as perspectivas teóricas do Feminismo Interseccional, amparadas por Lugones (2020), Curiel (2020), Audre Lorde (2019), bell hooks (2013), entre outros. Ao longo do diálogo entre as mulheres convidadas para conversar, em um programa cujo tema central era a maternidade, foram focalizados aspectos relativos ao papel social das mulheres, à noção de Feminismo Interseccional e à violência. Buscamos ver como o programa opera como uma pedagogia cultural, colaborando para as construções de representações de maternidade. Consideramos, então, que, se debruçar sobre as pedagogias culturais, as quais vêm contribuindo para a criação de estereótipos discriminatórios e cruéis, em filmes, quadrinhos, na literatura etc., talvez seja uma ferramenta com a qual possamos contar para revertê-las.

Palavras-chave: Pedagogias Culturais. Educação. Feminismo. Feminismo Interseccional.

\begin{abstract}
In this article, we analyze the cultural production of representations on motherhood, using theoretical contributions of Intersectional Feminism, based on discussions that took place in a podcast program named Mamilos. Our proposal is to revisit

Maria Lúcia Castagna Wortmann

Doutora em Educação pela Universidade Federal do Rio Grande do Sul (UFRGS). Professora adjunta da Universidade Luterana do Brasil. E-mail: wortmann@terra.com.br

Cláudia Schneider Marques

Mestra em Educação pela Universidade Federal do Rio Grande do Sul (UFRGS). E-mail: clausmarques@ gmail.com
\end{abstract}


the material developed as a master thesis, focusing, in this article, on Intersectional Feminism perspectives. We argue that the subjects learn to be who they are in the interaction with various media artifacts, based on authors attached to the Cultural Studies field, such as Giroux (2003), Kincheloe \& Steinberg (2004), Camozzato \& Costa (2013), Camozzato (2014), Camozzato; Oak; Andrade (2016). These theorists have concentrated on the so-called cultural pedagogies, a powerful tool of analysis. After a panoramic overview, in which we briefly present the original research, we point output concepts from Cultural Studies into dialogue with the perspectives of Intersectional Feminism, supported by Lugones (2020), Curiel (2020), Audre Lorde (2019), bell hooks (2013), and others. During the dialogue between the women invited to talk, in a program in which the main subject was motherhood, aspects related to the women's social role, the notion of Intersectional Feminism and the violence were focused. We plan to observe the way the program operates as a cultural pedagogy, contributing to the construction of representations of motherhood. We consider, then, that addressing the cultural pedagogies that operated the creation of discriminatory and cruel stereotypes in films, comics, literature etc., may be a tool in which we can count on to reverse them.

Keywords: Cultural Pedagogies. Education. Feminism. Intersectional Feminism.

\section{Introdução}

Examinamos, neste texto, valendo-nos dos aportes dos Estudos Culturais em Educação e do Feminismo Interseccional, representações de maternidade que são produzidas em um canal veiculado por um artefato cultural midiático que vem ganhando destaque, especialmente a partir dos anos 2010: o podcast. Amparadas em estudos conduzidos por Giroux (2003), Kincheloe \& Steinberg (2004) e, mais recentemente, por Camozzato \& Costa (2013), Camozzato (2014), Camozzato; Carvalho; Andrade (2016), viemos nos dedicando à compreensão de como operam as pedagogias culturais, que consideramos serem um recurso muito significativo de análise. Argumentamos que os sujeitos aprendem a ser quem são na interação com diversos artefatos da cultura, tais como filmes, revistas, brinquedos, moda, publicidade, mídias, que funcionam, nesse sentido, como pedagogias qualificadas como culturais. Nesse estudo, que se inspira nos Estudos Culturais, pensados a partir do pensamento pós-estruturalista, consideramos que o canal Mamilos de podcast atua como uma pedagogia cultural a qual ensina sobre a maternidade e os papéis atribuídos às mulheres mães, considerando, especialmente, visões imbuídas de um Feminismo Interseccional.

Nossa proposta, neste artigo, envolve analisar parte do material coletado e que se constituiu como o corpus de uma dissertação de mestrado, a partir de um olhar mais direcionado a questões específicas do Feminismo Interseccional. Dessa forma, procedemos a uma revisão das análises realizadas na dissertação a partir de um olhar interessado nas inter-relações entre os vários elementos que 
marcam qualquer sujeito social, estabelecendo, assim, outros critérios críticoanalíticos, amparadas, para tanto, por autoras e autores, tais como Curiel (2020), Lugones (2020), bell hooks (2013), entre outros.

Na primeira seção deste artigo, apresentaremos, de forma breve, o estudo conduzido em um voo panorâmico sobre os principais conceitos e autores abordados. Em seguida, apontamos para alguns dos direcionamentos revistos, salientando que esta revisão colocou em diálogo conceitos dos Estudos Culturais com as perspectivas do Feminismo Interseccional. Por fim, apresentamos algumas considerações finais e, como é inevitável, os questionamentos que permaneceram ou surgiram ao longo da análise, a fim de convidar outros pesquisadores a continuarem essas investigações.

\section{Aprendendo sobre maternidade no canal Mamilos}

O conceito de pedagogias culturais, que tem funcionado como uma importante ferramenta teórica do campo da Educação, surge no Brasil em trabalhos conduzidos a partir dos Estudos Culturais em Educação, no decorrer dos anos 1990. É importante lembrar que esse conceito se aplica, assim como Silva (200o, p. 89) assinalou, a qualquer "dispositivo cultural que, tal como a escola, esteja envolvido - em conexão com as relações de poder - no processo de transmissão de atitudes e valores". Camozzato e Costa (2013) associam esse conceito a uma disposição que denominaram como "vontade de pedagogia", que está implicada com a proliferação do pedagógico; ou seja, como as autoras registraram, tem-se a compreensão da "pedagogia como um traço, uma marca da contínua vontade de investir e atuar sobre todos os aspectos e âmbitos da vida dos sujeitos contemporâneos" (CAMOZZATO \& COSTA, 2013, p. 23).

Assumimos o entendimento de que os discursos circundantes nas sociedades contemporâneas operam moldando os sujeitos e promovem, constantemente, a sua inclusão/exclusão em determinadas classificações; isto é, os indivíduos aprendem a ser quem são, também, a partir dos artefatos culturais com os quais interagem e nos quais opera a pedagogia cultural, este "potente conceito acionado a partir do referencial dos Estudos Culturais” (ANDRADE, 2016, p. 19).

Consideramos, assim, que o canal Mamilos, de podcast, atua como uma pedagogia cultural. Esclarecemos que, por meio dessa mídia, são transmitidas informações em áudio, em diversos canais - os podcasts, normalmente, têm, em torno de si, uma ampla rede de conexões, formada pelas mídias sociais, como: Facebook, Instagram e Twitter, em cujas teias as discussões iniciadas nos programas continuam acontecendo. Também por meio dessas mídias sociais, os ouvintes são convidados, em diversas ocasiões, a participar dos programas, seja enviando relatos ou mesmo participando de conversas presenciais ou on-line, com os apresentadores. Essas informações tornam-se muito relevantes, na medida em que é a partir desses registros de comentários dos ouvintes, os quais podemos acessar pelas redes sociais 
ou pela leitura deles "no ar", feita por apresentadores, que conseguimos identificar, perceber e analisar o potencial pedagógico desses produtos midiáticos. Por meio dos comentários notamos a importância dos debates travados na programação e sua interferência real na vida dos ouvintes.

Questões de gênero permeiam este estudo, que focaliza, especialmente, no papel atribuído às mulheres-mães e suas identidades, pois o tema maternidade é amplamentediscutido no canal Mamilos, o qual foi criado em 2014 por Juliana Wallauer e Cris Bartis, publicitárias. O programa é intensamente interativo e, nas dinâmicas, é possível perceber discursos de diferentes ordens, as quais perpassam os temas narrados/discutidos e que argumentamos estarem atuando sobre as compreensões dos sujeitos relativamente às temáticas focalizadas. Aliás, uma estratégia frequente de mobilização das audiências desse programa inclui a solicitação de análise e revisão de suas práticas diárias e de seus posicionamentos diante do assunto abordado, e também o envio de comentários, de modo que possam fazer parte de uma rede capaz de tornar todos os interessados na temática mais próximos. Um exemplo dessa prática foi um programa sobre puerpério, o qual foi composto de relatos enviados pelo público. Tais relatos foram pedidos pelas apresentadoras por meio das redes sociais do canal.

Sobre este enredamento midiático, que se processa entre os produtores de mídia e seu público, cabe-nos referir estudos conduzidos por Jenkins, Ford e Green (2015):

Quando os membros do público propagam [...] conteúdo de uma comunidade para outra é porque têm interesse na propagação dessas mensagens. Eles estão adotando um material significativo para si em função de este ter valor dentro de suas redes sociais, além de facilitar as conversas que querem manter com seus amigos e familiares (JENKINS, FORD \& GREEN, $2015 \mathrm{~s} / \mathrm{p}$ ).

É possível dizer, então, que um processo como esse se direciona a construir, entre os "membros" do público, uma identidade que os une; e esse "laço de confiança" parece ser fundamental para que o conceito de pedagogia cultural opere de forma efetiva. Pode-se perceber como esse laço de confiança se estabelece no programa Mamilos, através dos comentários feitos pelos ouvintes. Embora, no episódio seguinte a este programa, as apresentadoras não tenham levado ao ar esses comentários, eles foram bastante numerosos nas redes sociais. No Instagram, por exemplo, vários deles se manifestaram, elogiando o tema e as discussões; mas uma participação chama a atenção especialmente: uma ouvinte marcou duas amigas nos comentários, indicando o episódio, e disse " $v c^{1}$ sabem $q$ amo mto elas! Deve estar ótimo!!!". A partir desses comentários, percebemos que, antes mesmo de ouvir o programa, a ouvinte já esperava algo bom e significativo, a ponto de indicar o programa para

1 Abreviações e gírias presentes nos comentários postados por ouvintes nas redes sociais do canal Mamilos. 
pessoas de seu círculo. Diversos comentários revelam quanto as pessoas aprenderam ao ouvir o episódio, como este: "eu amei e aprendi muito".

Assim, cada vez mais, se estabelece uma importante conexão entre os produtos da comunicação e a educação, e essa "hibridação entre Educação e Comunicação tem contribuído para uma significativa discussão sobre pedagogias, uma vez que é destacada a implicação de artefatos que compõem o que tem sido denominado de cultura da mídia na formação de sujeitos hoje" (ANDRADE \& COSTA, 2015, p. 52).

Como Paul du Gay ressaltou:

[...] significados não são apenas "enviados" pelos produtores e "recebidos", passivamente, pelos consumidores; pelo contrário, significados são ativamente produzidos no consumo, por meio do uso que cada pessoa faz desses produtos em sua vida diária (GAY et al. 1997, p. 5, tradução nossa).

Esses significados "produzidos no consumo" são perceptíveis nos comentários enviados pelos ouvintes à produção do programa. Não são raros os relatos de ouvintes que narram transformações em sua vida, rotina, e em seu modo de pensar e ver o que está ao seu redor, a partir de situações narradas no programa. Esses retornos dos ouvintes, sejam no formato de e-mails enviados ao programa ou nos comentários das redes sociais, nos permitem observar a pedagogia cultural operando de forma muito contundente.

\section{Sobre os procedimentos analíticos}

Antes de apresentar o episódio do canal Mamilos, sobre o qual nos debruçamos para a produção deste artigo, consideramos importante registrar, brevemente, nossas referências metodológicas. Pesquisas realizadas a partir de discursos produzidos em programas de podcast e de redes sociais estão em franco crescimento, mas são, relativamente, recentes. Ao mesmo tempo em que esse fato se apresenta como um desafio, visto que estamos empreendendo algo novo, esse também nos permite, do ponto de vista das pesquisas pós-estruturalistas conduzidas na linha de Estudos Culturais em Educação, usufruir de alguma liberdade e criatividade. Realizamos nossas análises embasadas nas metodologias de pesquisas pós-críticas em educação, cuja característica importante é "a de que o desenho metodológico de uma pesquisa não está (e nem poderia estar) fechado e determinado a priori [...]” (MEYER \& PARAÍSO, 2014, p. 22). Os caminhos metodológicos foram sendo construídos ao longo da pesquisa de mestrado, na coleta e organização de dados, e, posteriormente, no momento da escrita. 
Realizamos, inicialmente, a escuta repetida dos episódios do Programa, atentando, especialmente, para aspectos, temáticas e situações que se repetiam, nos diferentes episódios. Ao mesmo tempo, fomos organizando tabelas, primeiro com a totalidade dos episódios e suas datas de publicação, em seguida, selecionando aqueles que abordavam o tema da maternidade e, finalmente, com os episódios selecionados que, na dissertação, foram seis. Novas escutas desses seis episódios foram realizadas, a partir dos quais diversos trechos foram destacados. Tais trechos foram transcritos e organizados em uma nova tabela, na qual também foram registrados os comentários de ouvintes, referentes ao episódio, lidos pelas apresentadoras "no ar". Eles também foram salvos em formato de áudio, em pequenas citações sonoras - tanto na dissertação quanto neste artigo -, e estas estão indicadas pelo número do episódio e o momento exato em que a fala ocorreu, indicado pelos minutos e segundos.

Neste artigo, nos centramos na apresentação do episódio 147, intitulado Mães e Tabus. Além dos trechos que haviam sido transcritos e analisados no contexto da produção da já referida dissertação de mestrado, trouxemos, aqui, novos trechos, que nos permitiram aprofundar e intensificar o olhar para a questão do Feminismo Interseccional. De acordo com Paraíso (2014), um dos pressupostos das pesquisas pós-críticas é justamente o de que "o sujeito é um efeito das linguagens" (PARAÍSO, 2014, p. 31). Analisamos, portanto, o poder de transformação dos discursos que foram proferidos ao longo do episódio, relacionando-os com o rico arcabouço teórico que nos amparou nas reflexões acerca de gênero, raça, classe social, e das demais questões discutidas ao longo do texto.

Ainda embasadas pelas metodologias de pesquisas pós-críticas em educação, citamos Louro (2007) para registrar a importância de "desconfiar das certezas definitivas" (LOURO, 2007, p. 238). Inspiradas nesta asserção, buscamos problematizar representações que perpassaram os programas analisados, destacando a potência atribuída por nós à análise dos discursos os quais constituem e definem quem são as mulheres-mães que promovem, participam e ouvem o programa Mamilos. Utilizamonos da articulação de conceitos diversos para amparar e aprofundar nossas análises, ao longo dessa pesquisa, tendo também presente que, quando realizamos uma pesquisa, atentando para um contexto pós-moderno, é necessário que revisemos as metodologias utilizadas em períodos anteriores, quando as trocas e aprendizagens se davam de formas menos fluidas e variáveis, tal como registrou Paraíso (2014), ao ressaltar que:

Por isso, em nossas pesquisas, ampliamos nossas categorias de análise que deixaram de priorizar apenas classe social e passaram a atentar e operar com questões de gênero, sexualidade, raça/etnia, geração, idade, cultura, regionalidade, nacionalidade, novas comunidades, localidade, multiculturalidade etc. (PARAÍSO, 2014, p. 29). 
A partir dessa afirmação de Paraíso (2014), justificamos, mais uma vez, a importância de buscarmos colocar em articulação, nas análises conduzidas, conceitos de diferentes áreas do conhecimento, prática para a qual somos autorizados pelos Estudos Culturais. Argumentamos que, desse modo, ampliamos nossas compreensões acerca de como o educativo opera nas redes em que se tramam as compreensões em curso acerca dos sujeitos e do mundo contemporâneo.

A dissertação de mestrado a partir da qual se originou este artigo, foi iniciada com um trecho de uma letra de canção como epígrafe. Tal trecho afirma: "É o chão que define o calçado", metáfora da qual nos valemos para registrar que as metodologias vão se construindo ao longo da pesquisa e da escrita. Mas cabe, também, salientar que os diferentes caminhos podem exigir o uso de diferentes calçados; ou, ainda: determinados tipos de calçados podem nos levar a diferentes caminhos. E essas considerações vão ao encontro da reflexão de Louro (2007) ao assinalar a necessária desconfiança que devemos ter de todas as certezas definitivas as quais nos são apresentadas. Como a autora Louro (2007) ressaltou,

Conhecer, pesquisar e escrever nessa ótica significa resistir à pretensão de operar com "a verdade". Implica entender que qualquer verdade ou certeza (incluindo, obviamente, as nossas) está ancorada no que é possível conhecer num dado momento, portanto, é provisória, situada (LOURO, 2007, p. 241, grifos da autora).

\section{Maternidade, gênero e interseccionalidade no canal Mamilos de podcast}

Passemos, então, à análise de um dos episódios do canal Mamilos, no qual as duas apresentadoras e produtoras do programa, Juliana Wallauer e Cris Bartis, ambas publicitárias de formação, convidam duas mulheres² ativistas de Direitos Humanos, uma branca e outra negra, para debaterem tabus da maternidade. Esse episódio, de número 147, intitulado Mães e Tabus, foi publicado em 11 de maio de 2018. O episódio tem duração de quase 1 hora e 40 minutos, e inicia com um exercício proposto pelas apresentadoras de que todas conversem sobre suas mães.

Isis Carolina, mulher negra, mãe de Estela (8 anos), que precisou acompanhála durante a gravação do programa, falou sobre o ambiente violento no qual esteve inserida durante a infância. Segundo Isis, ela e os irmãos apanhavam muito da mãe. No entanto, ela afirma que, hoje:

A gente está completamente mergulhada nas pautas sobre feminismo, principalmente sobre feminismo e raça. Você começa

2 Convidadas: Rebeca Lerer - jornalista e ativista de direitos humanos. Isis Carolina - ativista do Coletivo AMEM, do coletivo Sistema Negro, assessora de Djamila Ribeiro e colaboradora na revista Elle Brasil. 
a refletir sobre o que levou ela a ser e ter feito tudo isso e todas as coisas que ela fez. Eu não bato na minha filha, por exemplo, e não que muitas vezes eu não tenha vontade (MAMILOS 147, 7:30).

Ela segue afirmando que, na idade adulta, sobretudo depois ter-se tornado mãe, ela passou a ter um olhar muito mais generoso em relação à sua própria mãe. Disse ela:

Hoje eu tenho um olhar muito mais humanizado para minha mãe, eu tento humanizar aquele indivíduo, que acima de tudo, era uma mulher que tinha desejos, que tinha vontade de, muitas vezes, não fazer nada. Às vezes ela não queria ficar com a gente e tudo bem. Porque ela tem esse direito de descansar. E de não pensar em ter que limpar nossa bunda e ter que fazer comida...Ela não tinha alternativas. Então eu tenho um olhar hoje, quando eu penso esse reflexo geracional, o que era antes e o que éagora... também porque ela não tinha consciência de gênero e raça também. Muitas vezes ela não sabia e não tinha condições de instrumentalizar a gente pra poder dar conta de tudo que também acontecia com a gente (MAMILOS 147, 9:50).

María Lugones (2020) abre seu artigo Colonialidade e gênero com as seguintes palavras, que elucidam muito bem os fatos narrados aqui:

Investigo a intersecção entre raça, classe, gênero e sexualidade na tentativa de entender a preocupante indiferença dos homens com relação às violências que, sistematicamente, as mulheres de cor sofrem: mulheres não brancas; mulheres vítimas da colonialidade do poder e, inseparavelmente, da colonialidade do gênero; mulheres que criam análises críticas do feminismo hegemônico, precisamente por ele ignorar a interseccionalidade das relações de raça/classe/sexualidade/gênero (LUGONES, 2020, p. 58).

Quando a convidada do programa, Isis Carolina, relata como a violência permeava a sua relação com sua mãe e o quanto, hoje, ela entende os fatores os quais a motivavam a agir daquela maneira, ou não permitiam a percepção de outras possibilidades e formas de agir, percebemos, de forma bastante evidente, a gama quase infinita de variáveis que estão associadas ao feminismo e às maternidades. A partir dessa constatação, evidencia-se a importância desse olhar mais atento, com lentes capazes de ampliar a visão do pesquisador e da pesquisadora para essa questão que tem muitas nuances.

O feminismo nasce de uma necessidade de luta das mulheres, mas é tão diverso e plural quanto o universo de mulheres existentes. É ingênuo acreditar que um feminismo único pudesse representar todas as pessoas do mesmo gênero. 
É natural, em uma sociedade machista, moralista, cristã e eurocêntrica, que as mulheres brancas tenham necessidades diferentes daquelas apresentadas pelas mulheres negras ou indígenas. A classe social também é fator de grande impacto nas lutas do feminismo. As necessidades de uma mulher negra, que mora na periferia e trabalha mais de 12 horas por dia, são muito diferentes das necessidades de uma mulher branca, de classe média, que trabalha meio turno.

Judith Butler (2017) problematiza essas questões e nos ajuda a melhor compreender esse ponto:

Se alguém "é" uma mulher, isso certamente não é tudo o que esse alguém é; o termo não logra ser exaustivo, não porque os traços predefinidos de gênero da "pessoa" transcendam a parafernália específica de seu gênero, mas porque o gênero nem sempre se constitui de maneira coerente ou consistente nos diferentes contextos históricos, e porque o gênero estabelece interseções com modalidades raciais, classistas, étnicas, sexuais e regionais de identidades discursivamente constituídas. Resulta que se tornou impossível separar a noção de "gênero" das interseções políticas e culturais em que invariavelmente ela é produzida e mantida (BUTLER, 2017, p. 21, grifos da autora).

A partir das colocações de Butler, podemos pensar que a demanda de estudos que focalizam os diversos feminismos e a interseccionalidade entre raça, gênero, classe social, é imensa e necessária.

A convidada Isis Carolina relata um caso de assédio que sofreu na infância, voltando da escola, e o quanto aquilo, embora tenha sido algo muito rápido, a incomodou por anos, deixando-a amedrontada por muito tempo. Mais uma vez, ela se refere ao fato de sua mãe não ter, na época, instrumentalização para ajudá-la a lidar com essas situações.

E ela assim relatou a situação:

Então, eu lembro que ela não tinha condições, porque ela não tinha acesso à informação e não estava debatendo sobre isso, sobre o feminismo e, muito menos, sobre o Feminismo Interseccional. Ela tinha medo. Ela tinha medo porque sabia, por que era, inclusive, pessoas que foram criadas, doutrinadas pelo Datena, entendeu? Já tinha pós-graduação em jornal Nacional. Então, sabia das situações diárias e cotidianas de violência, mas não sabia dialogar com a gente. Então eu sinto que a nossa educação, ela foi pautada muito pelo medo, mas era muito mais pelo medo da gente sofrer fora. Então, eu vou socar você, eu vou te arrebentar se você voltar 11 horas. Então a gente voltava muito mais pelo medo de ser socado por ela, mas entendendo depois de muitos anos, que depois você vai refletir e tem um olhar muito mais generoso também (MAMILOS 147, 11:00). 
O debate continuou e, ao longo da conversa, foram sendo elucidadas as diferentes dificuldades vividas por Isis, mulher negra, e Rebeca, Juliana e Cris Bartis, mulheres brancas. Evocamos, novamente, palavras de Lugones (2020), para melhor explicar essa diferença de condição:

Como já indiquei, a autodenominação mulheres de cor não é equivalente aos termos raciais impostos pelo Estado racista, e sim proposta em grande tensão com eles. Ainda que na modernidade eurocêntrica capitalista sejamos todos/as racializados/as e um gênero nos seja atribuído, nem todos/as somos dominados/as ou vitimizados/as por esse processo. O processo é binário, dicotômico e hierárquico. Kimberlé Crenshaw, eu e outras mulheres de cor feministas argumentamos que as categorias são entendidas como homogêneas e que elas selecionam um dominante, em seu grupo, como norma; dessa maneira, "mulher" seleciona como norma as fêmeas burguesas brancas heterossexuais, "homem" seleciona os machos burgueses brancos heterossexuais, "negro" seleciona os machos heterossexuais negros, e assim sucessivamente (LUGONES, 2020, p. 66).

Portanto, perceber que não se está incluída no grupo dominante, integrado por mulheres brancas, heterossexuais, de classe alta, a faz entender a necessidade de criar artimanhas para sobreviver fora dessas hegemonias. Já em outros casos, mesmo estando incluída nesse padrão identitário, há outros problemas que podem tomar uma dimensão relevante.

Dando continuidade aos relatos que as convidadas do programa fizeram sobre suas mães, Rebeca Lerer fala de como passou a infância distante da mãe, embora vivessem na mesma casa. Por ter se divorciado, a mãe de Rebeca precisava trabalhar muito (chegou a ter 5 empregos concomitantemente) e, por isso, Rebeca e o irmão passavam boa parte do tempo sem vê-la. Quando a mãe casou novamente, acolheu os filhos do novo marido, e Rebeca passou a ser a única menina na casa, o que resultava, segundo ela, em uma certa opressão, como pode ser observado em seu depoimento:

Eu tive que dar uma ruptura na minha casa, sabe? Eu vou ser a mulher que eu quiser ser, porque se depender dessa minha família judaica, classe média, branca, burguesa de São Paulo, o caminho é faça um bom casamento, tenha vários filhos, uma carreira... (MAMILOS 147, 18:40).

Rebeca questionou o fato de sua mãe não ter cuidado de si, de não ter feito planos para si mesma, pois trabalhava demais pela necessidade de manter a família. É importante registrar que essa é a realidade de muitas mulheres, as quais precisam abraçar essa tarefa da maternidade sozinhas, porque muitos homens abandonam seus filhos, suas famílias; e registrar, também, que essa condição, na maioria das 
vezes, causa culpa a essas mães, pois ainda preponderam nas sociedades discursos atrelados a um machismo estrutural, o qual naturaliza o fato de os cuidados do bebê serem responsabilidade exclusiva delas, as mulheres-mães.

A convidada Isis Carolina falou sobre as culpas que sente sobre o receio de não conseguir transcender o abismo existente, na época de sua mãe, entre a prática e o discurso. Ela diz que procura ter conversas sinceras com sua filha, a fim de prepará-la da melhor maneira para encarar a sociedade machista, racista, moralista e cristã na qual vivemos. Disse ela:

Eu tento achar essa linha que faz eu ser um indivíduo em que não exista um abismo entre a prática e o discurso, sabe, eu tento transcender esse abismo. Mas é muito difícil. Essa é a realidade. Eu tento estabelecer um diálogo muito sincero com minha filha. Principalmente sendo uma mãe-solo e uma mulher negra, eu não tenho alternativa, minha filha precisa saber que existe racismo. Porque não só ela já foi [vítima de racismo], como ela se depara com isso cotidianamente (MAMILOS 147, 32:35).

Isis, então, enfatizou a importância da informação e do diálogo, para instrumentalizar mulheres negras, preparando-as para o momento em que pudessem vir a ser vítimas de violência racial e de gênero. $O$ próprio fato dessa convidada ter precisado levar a filha para participar da gravação deste programa de podcast, onde aconteceria um debate sobre assuntos pesados, e com os quais a menina já tinha certa intimidade, por necessidade, já evidencia algumas questões importantes sobre a rotina materna, a sobrecarga de trabalho, as demandas relativas aos filhos e as oportunidades.

Ela relatou, então, algo que aconteceu com sua filha:

Não faz tempo, umas três semanas, ela chegou e disse: ah, estou chateada. Ela desenrolou bem, e aí eu percebo o quanto as nossas ações cotidianas influenciam porque ela conseguiu sair de uma situação racista com muito mais expertise do que eu na idade dela. Porque ah, sei quanto anos atrás eu fui vítima do mesmo rolê, de um grupinho de pessoas falando do meu cabelo e foi a mesma coisa com a Estela. Só que ela desenrolou, ela respondeu. Porque cotidianamente ela escuta, ela vê a gente em exercício do que a gente fala todos os dias, né (MAMILOS 147, 33:00).

Esse diálogo sincero com sua filha, defendido por Isis, revela-se potente, quando ele é vivenciado, experimentado no cotidiano. Como ela referiu, sua filha vê as lutas no "exercício diário". Evocamos palavras de Audre Lorde (2019), que traduzem essa vivência de uma forma muito poética. 
Quando entramos em contato com nossa ancestralidade, com a consciência não europeia de vida como situação a ser experimentada e com a qual se interage, aprendemos cada vez mais a apreciar nossos sentimentos e a respeitar essas fontes ocultas do nosso poder - é delas que surge o verdadeiro conhecimento e, com ele, as atitudes duradouras (LORDE, 2019, p. 46).

Retomamos o diálogo que se seguiu no mesmo programa, no qual as duas apresentadoras também contaram sobre suas infâncias e sobre suas mães. É importante ressaltar que quase todos os relatos focalizam mulheres que criaram seus filhos sozinhas e, em sua maioria, em condições financeiras bastante instáveis.

Cabe, então, registrar que, essas condições, tão distantes dos privilégios que se apresentam para alguns grupos, tornam ainda mais importantes as lutas feministas, especialmente as interseccionais. Isis também falou sobre as dificuldades de ser mãesolo, porque, segundo ela, "independentemente de ser casada ou não, ela [a mãe] é um indivíduo que historicamente é desumanizado” (MAMILOS 147, 45:31). Essa declaração se encaixa nas reflexões realizadas a partir de Lauxen e Quadrado (2018), que destacam que são atribuídas à mulher-mãe tarefas das mais variadas naturezas, e em volume desproporcional às tarefas atribuídas aos homens e pais. Daí a ideia de desumanização que as autoras indicam. E, se levarmos em conta a condição da mulher negra em nossa sociedade, essa desumanização tende a ser ainda maior, pois, como Lugones (2020) indicou, a condição de desumanização é imposta a todo sujeito que, de alguma forma, é oprimido em termos de poder.

Pode-se indicar, a partir desses depoimentos, uma representação ${ }^{3}$ da figura materna que inclui a responsabilidade de a mãe se dedicar, exclusivamente, aos filhos, e, como ressaltou a apresentadora Cris Bartis: "você leva o estado mãe para uma coisa sacra, que só reforça mais trabalho, mais exaustão, porque você tem que ser essa mãe do lugar santificado, sabe?” (MAMILOS 147, 49:19).

Isis fala, mais uma vez, sobre sua mãe e o quanto ela se tornou importante, atualmente, como rede de apoio.

A minha mãe, ela é maravilhosa, ela buscou sua emancipação, ela trabalha pra cacete e ela me deu todo um suporte, à minha família, depois que eu me separei. Porque eu também acho importante frisar que, como mulher negra, quando você se separa, a mulher negra como indivíduo ela é muito estigmatizada, muito estereotipada. Então, a gente, dentro de alguns espaços, a gente tem um corpo violentado, às vezes, no olhar, sabe? Eu.... andar com minha filha sozinha é historicamente um padrão, é naturalizado. Porque as mulheres negras, inclusive em termos de porcentagem, elas vivem essa solidão, né? Mas eu gosto sempre de

3 Estamos nos valendo da noção de representação cultural, tal como foi enunciada por Stuart Hall (2016). Nessa acepção, as representações atuam na constituição da subjetividade e da identidade dos seres e de suas definições como atores sociais. 
trazer o pensamento da bell hooks, que é isso também, eu acho que o processo de descolonização do pensamento está também em você viver esse processo só, pensando também: é o que eu gostaria, de ter, estar com alguém? Que é aquela lógica do "pelo menos ele lava a louça”, pelo menos, não! Eu não quero pelo menos. Ou a pessoa tá caminhando do meu lado, ou pelo menos eu faço isso sozinha (MAMILOS 147, 47:55).

Neste programa, apresentadoras e convidadas dialogaram sobre a dificuldade - dolorida, inclusive - de explicar a uma criança o que são racismo e assédio. Isis Carolina, que já apontei ser negra e ter uma filha negra, e Cris Bartis, que é branca e tem uma filha adotiva negra, comentaram sobre a insegurança e a angústia geradas por essa situação. E Cris Bartis, assim, se manifestou:

Trazer essa realidade crua é superdifícil. Colocar isso pra uma criança e explicar pra ela o que é racismo, por que o racismo acontece... pra ela identificar e saber reagir diante desse racismo. [...] Pra uma menina saber identificar o que é um assédio sem quebrar... não é despertar o pavor. Eu costumo falar coisas muito básicas, né. Ninguém pode te tratar diferente por causa da sua cor. E aí essas informações vão ficar cada vez mais elaboradas ao ponto que ela vai crescendo. Ninguém pode encostar no seu corpo de uma forma que te incomode. Se você achar esquisito, tá errado. E depois as coisas vão ganhando mais elaboração. Eu percebo que a gente, nesse afã de manter essa fantasia, que é tão bonita, que ainda acredita no Papai Noel [...] e ao mesmo tempo ela tem que saber o que é o racismo, o que é o assédio. Uma criança que ainda acredita na Fada do Dente. É muito doloroso ter que colocar isso para uma criança, sabe? Porém, é preciso fazer. É muito preciso fazer, porque começa muito jovem. E se ela sai de casa sem o instrumento básico pra reconhecer isso e para conseguir se proteger, é uma vez só, sabe? Infelizmente.

Sobre um caso de assédio na rua, Isis ainda comentou:

Audre Lorde fala isso, né, que o silêncio não vai nos proteger. E aí eu fiquei pensando nisso que.... né, eu crio uma filha negra e o Brasil, enfim, é um país que é estruturalmente machista e racista, logo, não reconhece a existência desses pilares. Então as pessoas não debatem, do meu ponto de vista, com seriedade sobre essas pautas. E quando eu falo "as pessoas não debatem", eu digo que as instituições não debatem, e que isso eu vou ampliando e vou trazendo pra minha realidade que é a escola. Por exemplo, a minha filha estuda numa escola particular que obviamente tem mais pessoas brancas do que negras e ela é vítima de racismo cotidianamente, mas ela não consegue e, 
muito menos eu, chegar na diretora e dizer que, só o fato de ela chegar num espaço que é majoritariamente ocupado por pessoas brancas já é um espaço violento. Porque é um espaço racista, então? Por que não tem mais pessoas negras dentro daquele espaço? Porque a sociedade ela é estruturante racista, logo, as pessoas negras não têm condições de ocupar aquele espaço porque elas não têm dinheiro. Então a luta de classe, a luta de gênero e a luta de raça, elas são transversais. Porque pra falar de classe, necessariamente você precisa falar de raça e, necessariamente você precisa falar de gênero, né? Porque se a sociedade é machista, logo, a gente está numa posição que é obviamente lá embaixo, a gente é a base ( MAMILOS 147, $83: 24)$.

Destaco, nas falas das duas interlocutoras, o propósito de apresentar, de forma escancarada, a realidade difícil e cruel do racismo e do machismo, mesmo para crianças pequenas, por entenderem ser essa uma forma de protegê-las. Por serem estruturais, o machismo e o racismo estão naturalizados em nosso contexto social, sendo a violência decorrente deles, muitas vezes, também naturalizada. Para que as crianças possam se defender dessa crueldade, como as debatedoras registraram, faz-se necessário romper com a ingenuidade da infância. E essas questões se intercruzam, ainda, a discussões acerca das classes sociais. Crianças negras que integram as camadas sociais mais pobres costumam ter menos oportunidades, especialmente quando advêm de lares em que as mães são vítimas de racismo, machismo e violência.

Recorremos, novamente, às palavras de Lugones (2020), pois essas podem nos auxiliar a compreender o que Isis Carolina nos diz quando afirma: "a luta de classe, a luta de gênero e a luta de raça são transversais”. Como ela registrou:

Devido à maneira como as categorias são construídas, a intersecção interpreta erroneamente as mulheres de cor. Na intersecção entre "mulher" e "negro" há uma ausência onde deveria estar a mulher negra, precisamente porque nem "mulher" nem "negro" a incluem. A intersecção nos mostra um vazio. Por isso, uma vez que a interseccionalidade nos mostra o que se perde, ficamos com a tarefa de reconceitualizar a lógica da intersecção, para, desse modo, evitar a separação das categorias existentes e o pensamento categorial (LUGONES, 2020, p. 66).

As debatedoras também trataram de questões estéticas relativas ao corpo negro. Elas relataram, por exemplo, que meninas negras, muitas vezes, não se reconhecem na TV, nas bonecas etc. Além disso, lhes parece que o cabelo crespo, a maquiagem e a tatuagem foram, e ainda são, muito negados às mulheres negras.

Isis lamenta essa situação, expressando-se da seguinte forma: 
Ou é magra, ou tem o tom de pele mais claro. Então você vê que o sistema racista, ele leva a gente o tempo todo, a negar nossa identidade. Então, essa luta é também para uma busca de nossa identidade que nos é negada o tempo todo. [...] até chorei esse dia. Eu não sei se eu chorei por ela ter sido vítima de racismo, que afeta dolorosamente a nossa autoestima, e faz com que naturalmente a gente cresça extremamente inseguro. A minha maior preocupação e que entra nesse lugar, também, que é exaustivo, é como a gente falar de situações tão complexas. Como que a minha filha, que é vítima de racismo 24 por 7 , no momento em que ela não se reconhece em que ela está num espaço em que ela não tem pessoas como ela, que ela não tá entre os iguais. Que os iguais estão em posição de desumanização. E aí o exercício é eu explicar pra ela que a sociedade é assim. Porque eu também não posso negar uma realidade (MAMILOS 147, 87:01).

E o debate se estendeu, nesse sentido, com todas concordando sobre a necessidade de informação e o quanto conversar sobre essas questões com meninas tão pequenas é doloroso. Rebeca Lerer salientou, inclusive, ensaios feitos com sua filha de 15 anos, de atitudes possíveis em caso de assédio, mostrando-lhe que essas podem variar, dependendo de onde ela está e de como a situação se desenrola. $\mathrm{O}$ programa nos indica que é muito cruel para as mulheres, de forma geral, lidar com essas situações, e isso é ainda mais cruel para as mulheres negras e, especialmente, para as mais pobres e com menos instrução, as quais estão, consequentemente, em muitos casos, menos preparadas para reagir.

Assim como Isis, evoco, mais uma vez, Audre Lorde (2019), em um excerto no qual ela discorre sobre a importância de se atentar para a instrumentalização das crianças frente a situações tais como as relatadas. Ressalta a autora:

De qualquer maneira, a experiência nos ensinou que a ação no presente também é necessária, sempre. Nossas crianças não podem sonhar, a menos que vivam, não podem viver, a menos que sejam cuidadas, e quem mais daria a elas o verdadeiro alimento sem o qual seus sonhos não seriam diferentes dos nossos? "Se vocês querem que mudemos o mundo um dia, precisamos pelo menos viver o suficiente para crescer!", grita a criança (LORDE, 2019, p. 48).

Trago, ainda, uma última transcrição da fala de Isis, na qual ela aprofunda aspectos relativos aos diálogos de instrumentalização que mantém com sua filha. Como ela ressaltou:

Eu já vou ter que abrir esse campo de diálogo pra fazer com que ela compreenda que ela sendo o corpo que é objetificado e ultra sexualizado, enfim, é animalesco até. É a carne mais 
barata do mercado, infelizmente, mas é. Então as relações que a minha filha pode estabelecer, pode ser em virtude de um processo, e essa é a minha maior preocupação, de um processo de crescimento antecipado. Porque ela é adultizada. Essa é a minha maior preocupação, eu quero que ela viva a infância dela sem necessariamente ser adultizada. E ela já é: nossa, que grandona, esses comentários são pavorosos, assim. Mas por outro lado, eu acho que o exercício, [...] isso aqui que a gente tá fazendo, é muito potente. Ela tá ouvindo, ela não é louca. Ela tá ouvindo aqui e ela tá bem ligada no que a gente tá falando. Eu quero que ela tenha uma consciência de que o corpo dela, ainda que ele seja ultra sexualizado, e que é, mas que ela entenda que com todo o acesso à informação, com todas as trocas que ela tem dessas redes de fortalecimento que estão junto comigo. To sozinha, sou mãe solo e a gente sabe das responsas que tem, mas existe uma rede que tá conectada comigo que, inclusive, possibilita que eu tenha trânsito e tenha vida profissional. Então eu confiar nessa rede e entender que, se ela estiver preparada, que não vai ser menos doloroso, mas ela já vai saber. Eu não sabia! Eu demorei pra me reconhecer negra. Eu era a moreninha, a mulata. Eu era qualquer coisa, menos negra. Porque ser negro no Brasil não é bom. Ninguém quer ser negro do Brasil (MAMILOS 147, 88:35).

Nessa última fala, como, aliás, também nas anteriores, destacamos a presença do pedagógico em operação neste programa. A própria convidada, Isis, refere-se à importância do tema que lá estava sendo tratado, quando afirma: "isso aqui que a gente tá fazendo é muito potente”. E nós completamos sua afirmação, destacando que essa importância foi enunciada de muitas formas neste programa, a exemplo das histórias de vida narradas pelas convidadas e pelas condutoras do programa. Por meio dessas histórias, foram apresentados exemplos das situações que as participantes intencionavam ressaltar. Além disso, estrategicamente, o programa busca suscitar a abordagem do tema em foco sob diferentes ângulos, porque, para ele, são convidadas a participar mulheres que, presumivelmente, viveram em diferentes contextos sociais. E essas interpelações são, nitidamente, pedagógicas, pois, a partir delas, vão sendo (re)construídos significados, que são colocados em circulação no programa, sobre o papel da mulher-mãe, bem como posições feministas interseccionais.

A informação, a consciência das condições nas quais se vive, as redes construídas nessa busca por conhecimento, por meio de um programa de podcast, podem ser muito importantes para essas discussões saírem de suas "bolhas" e atingirem mais mulheres, que sejam mães, negras, brancas. bell hooks destaca a importância da educação como um ato político, e conta que, nas escolas de ensino fundamental onde estudou, frequentadas somente por negros, ela teve a "experiência do aprendizado como revolução" (HOOKS, 2013, p.10).

Essa discussão se inicia em alguns nichos, tal como o citado por bell hooks, por necessidade, mas também precisa, por meio das redes, se espalhar, para adentrar 
em outros círculos, especialmente naqueles nos quais, usualmente, é dado destaque a posições mais conservadoras.

Como salientou Stuart Hall (2016), é importante que se busque operar na direção de reverter estereótipos os quais, historicamente, circulam em uma multiplicidade de produções culturais, para ser possível sensibilizar, provocar e, quem sabe assim, iniciar mudanças nas formas de representar e posicionar sujeitos ainda marcados e estigmatizados em sua diferença.

\section{Considerações finais}

A partir da análise dos diálogos entre as mulheres convidadas para conversar no programa de podcast Mamilos, focalizamos diversos pontos relativos à maternidade, ao papel da mulher, à violência e à noção de Feminismo Interseccional. Buscamos observar de que forma o programa opera como uma pedagogia cultural e de que maneiras esta pedagogia se efetiva no delineamento do programa, na dinâmica de desenvolvimento do mesmo e nas abordagens assumidas pelas participantes. Ou seja, o que entendemos como pedagógico não se restringe, apenas, à escuta do que é dito sobre o tema em foco pelas participantes agendadas, mas a atentar para como as próprias escolhas dessas participantes já se configuram de forma a permitir pautar variadas significações sobre o referido tema.

O programa, aqui examinado, abriu espaço para discussões sobre abuso, violência de gênero e racismo. As discussões deram voz a mulheres que viveram algumas dessas situações, bem como permitiram às/aos ouvintes se identificarem, ou não, com as problemáticas relatadas e a partir delas/es suscitarem reflexões sobre temas de extrema relevância no contexto brasileiro atual. Duas das convidadas participantes declararam ter o objetivo de instrumentalizar mais pessoas para lutar pelas causas entusiasticamente mencionadas por elas.

Nesse artigo, reconstruímos, parcialmente, as discussões e ressignificações feitas em um dos programas da série Mamilos de podcast. Queremos registrar a importância das discussões que focalizem os temas levantados no programa examinado por nós. Focalizar, neste estudo, o que lá foi dito, nos parece ser mais uma forma de ampliar tais discussões. Ao finalizar este artigo, queremos, ainda, registrar um fato ocorrido na véspera do Dia da Consciência Negra: um homem negro foi espancado até a morte por dois seguranças brancos em um supermercado na cidade de Porto Alegre/RS. Este não é um acontecimento pontual. Em uma sociedade machista, racista, moralista e doente como a nossa, na qual fatos como esse acontecem e a violência contra mulheres é frequentemente noticiada, certamente é preciso que os estudos acadêmicos também se voltem intensamente à discussão de como significados tais como o assinalado são justificados e se gestam. É também importante indicar a relevância de que estudos se ocupem da análise de produções 
culturais nas quais tais questões são focalizadas. Talvez essa seja uma maneira de tentar sensibilizar um maior número de pessoas para tais problemáticas, as quais proliferam em uma sociedade endurecida pelo ódio e pela discriminação. Debruçarse, então, sobre as pedagogias culturais que operaram a criação de estereótipos discriminatórios e cruéis em filmes, quadrinhos, na literatura etc., talvez seja uma ferramenta com a qual possamos contar para revertê-las.

\section{Referências Bibliográficas}

ANDRADE, Paula Deporte de. A invenção das pedagogias culturais. In: Pedagogias Culturais: a arte de produzir modos de ser e viver na contemporaneidade. Curitiba: Appris Editora, 2016, p. 19-32.

ANDRADE, Paula Deporte de; COSTA, Marisa Vorraber. Usos e possibilidades do conceito de pedagogias culturais em estudos culturais em educação. Canoas: Textura, v. 17, no 34.2015 , p. 48-63.

BUTLER, J. Problemas de gênero: feminismo e subversão da identidade. Rio de Janeiro: Civilização Brasileira, 2017.

CAMOZZATO, Viviane Castro; COSTA, Marisa Vorraber. Vontade de pedagogia: pluralização das pedagogias e condução dos sujeitos. Cadernos de Educação, v. 44, p.22-44, 2013.

GAY, Paul Du et al. Doing Cultural Studies: The story of the Sony Walkman. Sage Publications (in association with the Open University). 1997.

GIROUX, H. Atos Impuros. Porto Alegre: ArtMed, 2003.

HALL, Sturart. O espetáculo do outro. In: HALL, S. Cultura e Representação. Rio de Janeiro: Ed. PUC- Rio: Apicuri, 2016.

HALL, Sturart. O papel da representação. In: HALL, S. Cultura e Representação. Rio de Janeiro: Ed. PUC- Rio: Apicuri, 2016.

HOOKS, B. Ensinando a transgredir: a educação como prática da liberdade. São Paulo: Martins Fontes, 2013.

JENKINS, Henry; FORD, Sam; GREEN, Joshua. Cultura da conexão: criando valor e significado por meio da mídia propagável. Aleph, 2015. E-book.

LORDE, A. Irmã outsider. Belo Horizonte: Autêntica Editora, 2019. 
LOURO, G, L. Conhecer, escrever, pesquisar. Educação, Sociedade E Culturas, n 25, 2007, p. 235-245.

LUGONES, M. Colonialidade e gênero. In: HOLLANDA, H.B. et al. Pensamento feminista hoje: perspectivas decoloniais. Rio de Janeiro: Bazar do Tempo, 2020.

MEYER, D, E; PARAÍSO, M, A. Metodologias de pesquisas pós-críticas ou Sobre como fazemos nossas investigações. IN: MEYER, D, E; PARAÍSO, M, A. (org.) Metodologias de pesquisas pós-críticas em educação. Belo Horizonte: Mazza Edições, 2014.

PARAÎSO, M, A. Metodologias de pesquisas pós-críticas em educação e currículo: trajetórias, pressupostos, procedimentos e estratégias analíticas. IN: MEYER, D, E; PARAÍSO, M, A. (org.) Metodologias de pesquisas pós-críticas em educação. Belo Horizonte: Mazza Edições, 2014.

SILVA, Tomaz Tadeu da. Teoria cultural e educação - um vocabulário crítico. Belo Horizonte: Autêntica, 2000.

STEINBERG, S \& KINCHELOE, J. Kindercultura; a construção da infância pelas grandes corporações. In Silva, L.H. (org). Identidade social e a construção do conhecimento. Porto Alegre: SMED, 1997.

MAMILOS 147 - https://www.b9.com.br/shows/mamilos/mamilos-147-maes-etabus/ acesso em 22/11/2020.

Recebido em 21/03/2021.

Aceito em 12/06/2021. 